\title{
A Rare Case of Multipathogenic Pneumonia in a Patient With Human Immunodeficiency Virus
}

\author{
Ahmad Al-Shyoukh ${ }^{1}$, Moustafa Younis ${ }^{2}$, Mohamed Warsame ${ }^{3}$, Ashraf Gohar ${ }^{4}$ \\ 1. Internal Medicine, University of Missouri-Kansas City School of Medicine/Saint Luke's Health System, Kansas City, \\ USA 2. Internal Medicine, University of Missouri-Kansas City School of Medicine, Kansas City, USA 3. Infectious \\ Disease, Mayo Clinic, Rochester, USA 4. Pulmonary and Critical Care and Sleep, University of Missouri-Kansas City \\ (Hospital Hills Campus), Kansas City, USA
}

Corresponding author: Ahmad Al-Shyoukh, alshyoukha@umkc.edu

\begin{abstract}
The incidence of acquired immunodeficiency syndrome (AIDS)-related opportunistic infections has declined dramatically following the introduction of potent antiretroviral therapy (ART). However, pulmonary infections remain a significant cause of morbidity and mortality. The spectrum of pulmonary disease that can affect patients with human immunodeficiency virus (HIV) is wide and includes opportunistic infections with many bacterial, fungal, viral, and parasitic organisms. In this case, we present a 65 -year-old woman with HIV, non-compliant with ART, who presented with subacute melena, fatigue, dyspnea, and hemoptysis. After extensive evaluation, she was found to have pneumonia caused by four different pathogens: Strongyloides stercoralis, Pneumocystis jirovecii, Cytomegalovirus (CMV), and Pseudomonas aeruginosa. She received trimethoprim-sulfamethoxazole, steroids, and ivermectin. However, her clinical condition did not improve and she passed away.
\end{abstract}

Received 06/26/2020 Review began $07 / 05 / 2020$ Review ended 07/14/2020 Published 07/21/2020

(c) Copyright 2020

Al-Shyoukh et al. This is an open access article distributed under the terms of the Creative Commons Attribution License CC-BY 4.0 , which permits unrestricted use, distribution, and reproduction in any medium, provided the original author and source are credited.
Categories: HIV/AIDS, Infectious Disease, Pulmonology

Keywords: human immunodeficiency virus, pneumocystis carinii pneumonia, cytomegalovirus penumonia, opportunistic infection, strongyloides stercoralis

\section{Introduction}

Acquired immunodeficiency syndrome (AIDS)-related opportunistic infections have declined in incidence after antiretroviral therapy (ART) was introduced. Lung disorders that happen in patients with human immunodeficiency virus (HIV) vary and include a spectrum of multiple opportunistic infections [1]. They may include bacterial, viral, fungal, and parasitic etiologies, or a combination [2]. Bacterial pneumonia remains very common in HIV patients. However, consideration for other opportunistic infections is necessary. Herein, we present a rare case of pneumonia caused by four different pathogens: Strongyloides stercoralis, Pneumocystis jirovecii, Cytomegalovirus (CMV), and Pseudomonas aeruginosa.

\section{Case Presentation}

A 65-year-old female patient with past medical history of HIV infection, hypothyroidism, and medication non-adherence presented to the emergency department (ED) with fatigue and dark stools for two days.

On admission, she reported diffuse abdominal pain, generalized weakness, nausea, non-bilious non-bloody vomiting, hemoptysis, shortness of breath, chronic anorexia, and weight loss. She denied fever, chills, chest pain, diarrhea, or hematuria. She has lived in the Midwest for the past 12 years, previously lived in Mexico. She denied any recent travel, sick contacts, tick bites, camping, hiking, or drinking untreated water.

On examination, her vitals were within normal limits, she appeared cachectic, and had right basilar crackles. The patient did not have a rash.

Complete blood count was remarkable for normocytic anemia with a hemoglobin $(\mathrm{Hb})$ of $6.0 \mathrm{~g} / \mathrm{dL}$ with lymphopenia and normal eosinophil count (Table 1). Her last CD4 count was 19 cells/ $\mu \mathrm{L}$ about five months prior to presentation with a viral load of $1,690,000$ copies $/ \mathrm{mL}$. 


\section{Cureus}

Lab

Sodium

Potassium

Chloride

$\mathrm{CO}_{2}$

Creatinine

Blood urea nitrogen

Lactate dehydrogenase

Procalcitonin

Hemoglobin

Mean corpuscular volume

White blood cell count

Lymphocytes \%

CMV DNA PCR

BAL Pneumocystis jirovecii PCR

QuantiFERON Gold

Syphilis antibody

Urine histoplasma antigen

Blood cryptococcal antigen
Result

$123 \mathrm{mmol} / \mathrm{L}$

$3.2 \mathrm{mmol} / \mathrm{L}$

$93 \mathrm{mmol} / \mathrm{L}$

$16 \mathrm{mmol} / \mathrm{L}$

$0.80 \mathrm{mg} / \mathrm{dL}$

$14 \mathrm{mg} / \mathrm{dL}$

181 units/L

$0.11 \mathrm{ng} / \mathrm{mL}$

$6.0 \mathrm{~g} / \mathrm{dL}$

$93 \mathrm{fL}$

$7.70 \times 10^{3} / \mathrm{cm}^{3}$

$4.2 \%$

$80,202 \mathrm{IU} / \mathrm{mL}$

1,882 copies/mL

Indeterminate

Negative

Negative

Negative

\section{TABLE 1: Laboratory abnormalities}

CMV, cytomegalovirus; PCR, polymerase chain reaction; BAL, bronchoalveolar lavage

An arterial blood gas was obtained. $\mathrm{pH}$ was $7.48, \mathrm{PaCO}_{2}$ was $24.4, \mathrm{PaO}_{2}$ was 73.3 at $\mathrm{FiO}_{2}$ of $24 \%$, and $\mathrm{HCO}_{3}$ was 17.9. The alveolar-arterial gradient was $67.3 \mathrm{mmHg}$. CT of her abdomen with contrast and chest without contrast demonstrated severe colitis and diffuse bilateral ground-glass opacities with mildly enlarged mediastinal lymph nodes (Figure 1). 


\section{Cureus}
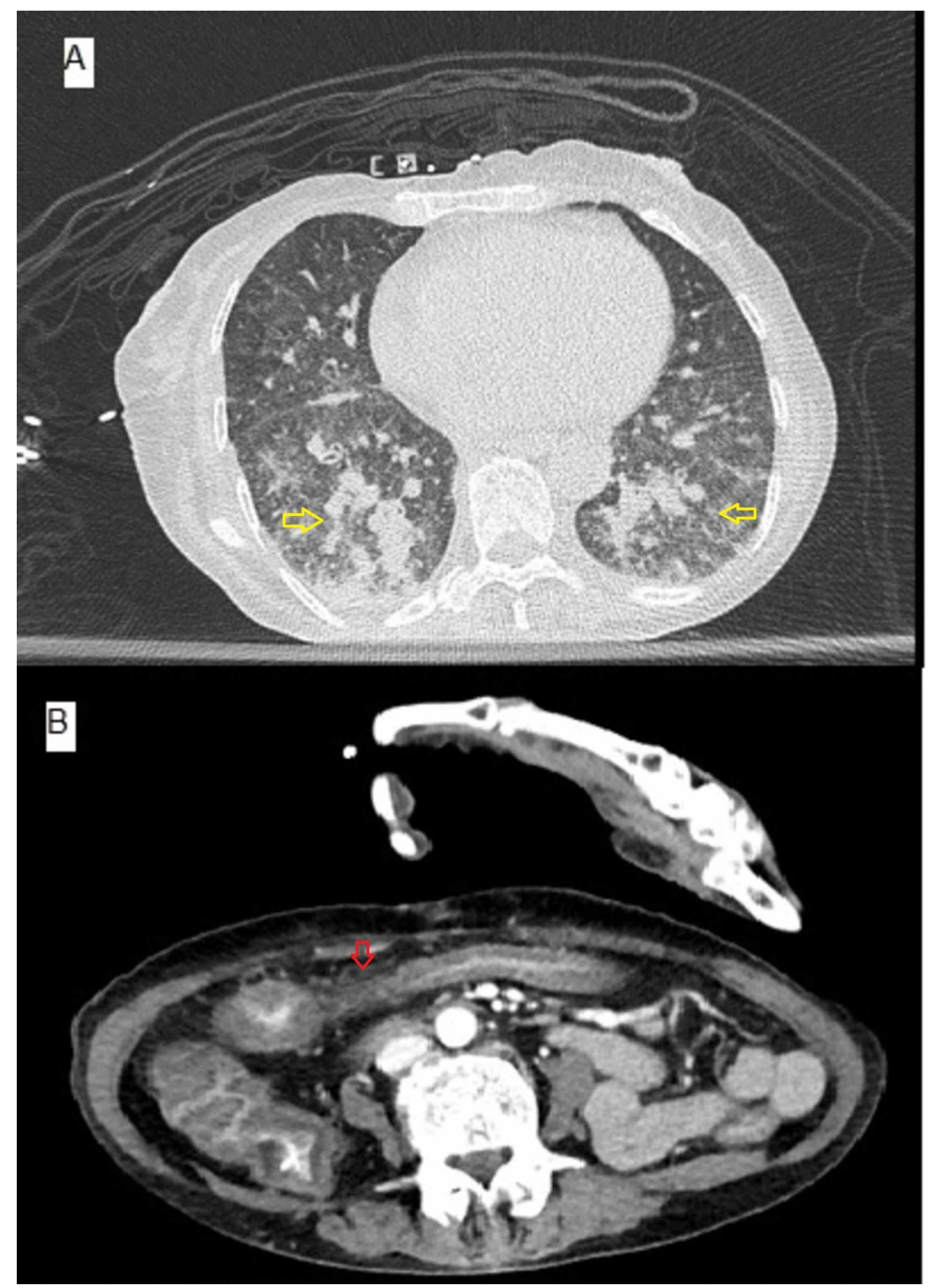

FIGURE 1: (A) CT chest with bilateral ground-glass opacities (yellow arrows). (B) CT abdomen with colitis (red arrow).

The patient was transfused two units of packed red blood cells and was started on intravenous (IV) levofloxacin and metronidazole for colitis and community-acquired pneumonia. We empirically started Pneumocystis pneumonia (PCP) treatment with trimethoprim-sulfamethoxazole and prednisone due to high clinical suspicion.

Blood cultures including fungal blood cultures were negative. Upper endoscopy and colonoscopy revealed duodenitis and moderate colitis, and biopsies were taken. On hospital day (HD) 3, bronchoscopy was performed with bronchoalveolar lavage (BAL). Subsequently, eosinophilia was noted on HD4 only. On HD 7, BAL was positive for PCP with a PCR of 1,882 quantitative copies/mL. BAL culture grew Pseudomonas aeruginosa, and cytology revealed parasitic larvae consistent with Strongyloides stercoralis and CMV inclusion bodies. The patient was subsequently started on ivermectin. CMV blood polymerase chain reaction (PCR) was positive with 80,202 IU/mL. She was treated with IV ganciclovir. On HD 10, duodenal biopsy also visualized Strongyloides stercoralis. Her respiratory and hemodynamic status steadily declined, and she subsequently developed disseminated intravascular coagulation and septic shock requiring transfer to the intensive care unit. After extensive discussion with the patient's family, we withdrew care and proceeded with comfort measures. The patient died shortly after. 


\section{Discussion}

We present a rare case of multipathogenic pneumonia caused by four different organisms in a woman with HIV. To our knowledge, there were no available reports of patients presenting with four different organisms at once.

The incidence of AIDS-related opportunistic infections has declined dramatically following the introduction of potent ART $[1,3,4]$. However, pulmonary infections remain a significant cause of morbidity and mortality [1]. Although the spectrum of pulmonary infections is broad and includes opportunistic infection with many bacterial, fungal, viral, and parasitic organisms, bacterial pneumonia remains the most common cause of pneumonia in patients with HIV [1,2]. Prompt appropriate diagnosis and consideration for the possibility of a multipathogenic pneumonia is essential in severely immunosuppressed patients.

Consistent with our patient, patients with HIV with a CD4 count $<50$ cells/ $\mu \mathrm{L}$ either not receiving or failing ART are at higher risk for CMV infection and/or reactivation [1,5,6]. CMV pneumonitis is uncommon, and its diagnosis is challenging as the signs and symptoms of CMV pneumonia are non-specific $[1,2,5,6]$. Radiological features include diffuse interstitial or alveolar infiltrates [1,2,6,7]. As a result of viral shedding, it is common for CMV to present in the BAL of patients with HIV; thus, its presence is insufficient for the diagnosis of invasive CMV pneumonitis. The diagnosis is confirmed once BAL cytology or lung biopsy demonstrates cells with inclusion bodies, after other etiologies are excluded $[1,2,6]$. As such, it is an extremely rare finding and was reported in only 5\%-8\% of HIV patients undergoing BAL [5]. CMV coinfection has been previously reported in the literature with PCP [8]. CMV pneumonia should be treated similar to other tissue-invasive CMV disease with full treatment doses of antivirals such as IV ganciclovir or IV foscarnet, and the duration of therapy depends on the severity of disease, as well as the clinical and virologic response to treatment ranging from 14 to 28 days or longer $[1,6]$.

CMV pneumonia along with Strongyloides sterocoralis has been reported before in a kidney transplant recipient on immunosuppression [9]. Strongyloides stercoralis is a parasitic nematode that causes gastrointestinal (GI), pulmonary, and disseminated infection in humans. Prevalence is highest in tropical climates and in the southeast part of the US. In a prospective study in the US, $25 \%$ of HIV cases were seropositive for Strongyloides stercoralis [10]. Larvae penetrate the skin and are then transmitted through the blood to the lungs where it ascends the tracheobronchial tree and is eventually swallowed entering the GI tract to lay eggs. Eggs hatch into larvae, which are either excreted in the stool or reinfect the same host through the same cycle $[1,11]$. It mostly manifests as a chronic infection in immunocompetent hosts but can lead to hyperinfection in immunocompromised patients. Hyperinfection is characterized by rapid uncontrolled multiplication of Stronglyoides, resulting in higher disease burden where patients acutely develop severe GI or pulmonary manifestations. Radiologically, bilateral pulmonary interstitial infiltrates are seen. Although eosinophilia is a common finding in chronic infection, it is usually absent in the setting of hyperinfection syndrome $[1,12]$. Interestingly, peripheral eosinophilia was initially absent in our patient and showed on HD4 following manipulation through bronchoscopy. Hyperinfection syndrome is promoted by the use of corticosteroids as we note in our patient [11]. Her respiratory status decompensated within few days of admission suggesting that steroids initiated on admission might have contributed. The diagnosis of chronic strongyloidiasis is challenging due to the low sensitivity of serology and stool microscopy. In contrast, hyperinfection syndrome is easier to diagnose as large number of larvae are seen in bodily fluids. Management includes supportive care along with anthelmintic medication such as ivermectin or albendazole for at least two weeks [1,11]. Ivermectin results in more cure and is well tolerated [13]. Furthermore, it is important to initiate empiric antibiotics against enteric gram-negative bacteria as Strongyloides may facilitate entry of enteric organisms into the systemic circulation.

Pseudomonas aeruginosa is a common bacterial etiology in pneumonia particularly in patients with CD4 $<100$ cells/ $\mu \mathrm{L}$ [2]. Facilitated by Strongyloides, we suggest that Pseudomonas aeruginosa disseminated from the GI tract to the lungs causing a superimposed pneumonia. Although our patients' blood cultures were negative, transient bacteremia is a possibility.

PCP is the most common AIDS-defining illness in the US. Its incidence is declining with increased use of ART and PCP prophylaxis but it continues to infect patients unaware of their HIV status or those not adhering to ART or prophylaxis [2,4]. More than $90 \%$ of cases in adults occur in those with CD4 count $<200$ cells/ $\mu \mathrm{L}[2]$. Most patients have an elevated lactate dehydrogenase (LDH), but it can also be normal such as in our patient. It also presents with bilateral interstitial infiltrates on chest imaging, as in our patient; however, diagnosis requires visualization of cysts on either induced sputum or BAL samples $[2,14]$. The firstline treatment for all severities is trimethoprim-sulfamethoxazole for 21 days. Alternatives for moderate to severe disease include IV pentamidine, clindamycin, and primaquine, and for mild disease include trimethoprim with dapsone, clindamycin with primaquine, or atovaquone. Corticosteroids are also recommended for patients with moderate to severe disease, with $\mathrm{PaO}_{2}$ below $70 \mathrm{mmHg}$ on room air, and/or alveolar-arterial gradient above $35 \mathrm{mmHg}$ [14].

\section{Conclusions}

We describe a rare case of HIV-related pneumonia caused by four different pathogens. Multipathogenic 
pneumonia in severely immunocompromised patients presents a diagnostic and management dilemma and high degree of clinical suspicion is required. Careful clinical evaluation, early diagnosis, and management of pneumonia in HIV patients are pivotal and time sensitive. Considering multiple etiologies in immunocompromised patients is necessary and early bronchoscopy is recommended.

\section{Additional Information \\ Disclosures}

Human subjects: Consent was obtained by all participants in this study. Conflicts of interest: In compliance with the ICMJE uniform disclosure form, all authors declare the following: Payment/services info: All authors have declared that no financial support was received from any organization for the submitted work. Financial relationships: All authors have declared that they have no financial relationships at present or within the previous three years with any organizations that might have an interest in the submitted work. Other relationships: All authors have declared that there are no other relationships or activities that could appear to have influenced the submitted work.

\section{References}

1. Skalski JH, Limper AH: Fungal, viral, and parasitic pneumonias associated with human immunodeficiency virus. Semin Respir Crit Care Med. 2016, 37:257-266. 10.1055/s-0036-1578802

2. Huang L, Crothers K: HIV-associated opportunistic pneumonias. Respirology. 2009, 14:474-485. 10.1111/j.1440-1843.2009.01534.x

3. Wolff AJ, O'Donnell AE: Pulmonary manifestations of HIV infection in the era of highly active antiretroviral therapy. Chest. 2001, 120:1888-1893. 10.1378/chest.120.6.1888

4. Crothers K, Thompson BW, Burkhardt K, et al.: HIV-associated lung infections and complications in the era of combination antiretroviral therapy. Proc Am Thorac Soc. 2011, 8:275-281.

5. Poh KC, Zheng S: A rare case of CMV pneumonia in HIV-infection . Respir Med Case Rep. 2019, 28:100945. 10.1016/j.rmcr.2019.100945

6. Guidelines for the prevention and treatment of opportunistic infections in HIV-infected adults and adolescents. Recommendations from the Centers for Disease Control and Prevention, the National Institutes of Health, and the HIV Medicine Association of the Infectious Diseases Society of America. (2020). Accessed: July 21, 2020: https://aidsinfo.nih.gov/contentfiles/lvguidelines/adult_oi.pdf.

7. Salomon N, Perlman DC: Cytomegalovirus pneumonia. Semin Respir Infect. 1999, 14:353-358.

8. Korkmaz Ekren P, Töreyin ZN, Nahid P, et al.: The association between Cytomegalovirus co-infection with Pneumocystis pneumonia and mortality in immunocompromised non-HIV patients. Clin Respir J. 2018, $12: 2590-2597$.

9. Elzein FE, Alsaeed M, Ballool S, Attia A: Strongyloides hyperinfection syndrome combined with Cytomegalovirus infection. Case Rep Transplant. 2016, 2016:1786265. 10.1155/2016/1786265

10. Nabha L, Krishnan S, Ramanathan R, et al.: Prevalence of Strongyloides stercoralis in an urban US AIDS cohort. Pathog Glob Health. 2012, 106:238-244. 10.1179/2047773212Y.0000000031

11. Nutman TB: Human infection with Strongyloides stercoralis and other related Strongyloides species . Parasitology. 2017, 144:263-273. 10.1017/S0031182016000834

12. Requena-Méndez A, Buonfrate D, Gomez-Junyent J, Zammarchi L, Bisoffi Z, Muñoz J: Evidence-based guidelines for screening and management of Strongyloidiasis in non-endemic countries. Am J Trop Med Hyg. 2017, 97:645-652. 10.4269/ajtmh.16-0923

13. Henriquez-Camacho C, Gotuzzo E, Echevarria J, et al.: Ivermectin versus albendazole or thiabendazole for Strongyloides stercoralis infection. Cochrane Database Syst Rev. 2016, 1:CD007745. 10.1002/14651858.CD007745.pub3

14. Huang YS, Yang JJ, Lee NY, Chen GJ, Ko WC, Sun HY, Hung CC: Treatment of Pneumocystis jirovecii pneumonia in HIV-infected patients: a review. Expert Rev Anti Infect Ther. 2017, 15:873-892. 10.1080/14787210.2017.1364991 